\title{
Differences in the Methyl Ester Distribution of Homogalacturonans from Near-Isogenic Wheat Lines Resistant and Susceptible to the Wheat Stem Rust Fungus
}

\author{
Nicola Wiethölter, ${ }^{1}$ Barbara Graeßner, ${ }^{2,3}$ Manfred Mierau, ${ }^{2}$ Andrew J. Mort, ${ }^{3}$ Bruno M. Moerschbacher ${ }^{1}$ \\ ${ }^{1}$ Institut für Biochemie und Biotechnologie der Pflanzen, Westfälische Wilhelms-Universität Münster, Hindenburgplatz 55, \\ 48143 Münster, Germany; ${ }^{2}$ Institut für Biologie III, Rheinisch-Westfälische Technische Hochschule Aachen, Worringer Weg \\ 1, 52056 Aachen, Germany; ${ }^{3}$ Department of Biochemistry and Molecular Biology, Oklahoma State University, 246 Noble \\ Research Centre, Stillwater, OK 74078, U.S.A.
}

Submitted 6 May 2003. Accepted 16 June 2003.

Plants possess an efficient nonself surveillance system triggering induced disease resistance mechanisms upon molecular recognition of microbial invaders. Successful pathogens have evolved strategies to evade or counteract these mechanisms, e.g., by the generation of suppressors. Pectic fragments produced during host cell wall degradation can act as endogenous suppressors of the hypersensitive response in wheat leaves. We have isolated and characterized homogalacturonans from cell walls of two wheat cultivars susceptible to the stem rust fungus, Puccinia graminis f. sp. tritici, namely cvs. Prelude and Marquis, and from nearisogenic lines of both cultivars containing the Sr5-gene for hypersensitive rust resistance. Two independent approaches were used to compare their methyl esterification: i) immunochemistry using the monoclonal antibodies JIM5, JIM7, PAM1, and LM7 and ii) chromatography of oligogalacturonides representing stretches of contiguous nonmethyl-esterified GalA residues. The results clearly indicate a significant difference in the homogalacturonans from susceptible and resistant wheat lines. The difference can best be explained by assuming a nonrandom and more blockwise distribution of the methyl esters in the homogalacturonans of susceptible wheat cultivars as compared with a presumably more random distribution in the nearisogenic resistant lines. Possible consequences of this difference for the enzymatic generation of endogenous suppressors are discussed.

Additional keyword: pectin.

Plant cells have evolved a sophisticated nonself surveillance system aimed at recognizing potential pathogens by the molecular recognition of typical surface components of the foreign organisms. Fungal invaders are easily recognized by their exposed cell walls containing typical compounds such as chitin and $\beta-1,3-\beta-1,6$-glucans that are not present in plant cell walls (Boller 1995; Côté et al. 1998). Successful plant pathogenic fungi must have evolved effective counter strategies to escape or circumvent the nonself surveillance system of their host plants. The most sophisticated strategies are found among the obligately biotrophic plant pathogens such as the rust fungi, which are highly specialized for and highly adapted to their re-

Corresponding author: B. M. Moerschbacher; Telephone: $+49-251-832$ 47 94/91; Fax: +49-251-832 83 71; E-mail: moersch@uni-muenster.de. spective host plants (Mendgen 1996). These fungi differentiate a complex series of infection structures used for directional germ tube growth on the surface of a host leaf in order to quickly and reliably reach a plant stoma. The infection structures further serve penetration into the host tissue via the stomatal opening, colonization of the intercellular spaces of the host leaves, and penetration of the host cell walls in order to reach the intracellular nutrient pool needed for fungal growth and reproduction.

It has recently been shown that at least some rust fungi, such as the wheat stem rust fungus and the broad bean rust fungus, change the surface properties of their cell walls upon penetration into the host leaf (El Gueddari et al. 2002). While the epiphytic infection structures of these rust fungi, namely germ tube and appressorium, contain chitin in their cell walls, the endophytically growing infection structures, namely substomatal vesicle and infection hyphae, expose chitosan on their surface. It has been assumed that this change in surface properties is an attempt of the rust fungi to evade their host plant's chitin-based nonself surveillance system. However, wheat plants appear to have reacted to this fungal strategy by evolving a recognition system for both chitin and chitosan that will lead to the elicitation of induced disease resistance reactions (Vander et al. 1998), namely the rapid and local cell death of penetrated host cells called hypersensitive reaction (Moerschbacher and Reisener 1997).

Although these and other general elicitors are potentially active in susceptible and resistant wheat plants (Moerschbacher et al. 1989; Sutherland et al. 1989; Vander et al. 1998), there are still compatible interactions between certain races of the wheat stem rust fungus and certain wheat cultivars resulting in undisturbed fungal development and, eventually, sporulation within the host leaf tissue. Clearly, in these interactions, the fungus must evade or counteract the plant's active defense system induced by the general elicitors (Knogge 1997; Moerschbacher and Reisener 1997).

There is increasing evidence that the wheat stem rust fungus is generating an endogenous suppressor of disease resistance elicitation when penetrating the plant cell wall to produce the nutrient-uptaking haustoria in the pericellular space of the host cells (Moerschbacher et al. 1990). Cell wall penetration appears to be an enzymatic process (Chong et al. 1981), and pectin-degrading enzymes involved in the softening of the plant cell wall might be responsible for the generation of suppressoractive pectic oligomers. It has recently been shown that small pectic oligomers are potent suppressors of elicitor-induced dis- 
ease resistance reactions in wheat leaves (Moerschbacher et al. 1999).

On the basis of these results, we have put forward the 'pectin hypothesis,' postulating differential enzymatic breakdown of wheat pectins upon rust invasion of resistant versus susceptible host tissue, leading to the generation of suppressor-active pectic oligomers in susceptible plants only. In contrast, in resistant wheat cultivars, failure to produce suppressor-active pectic oligomers may lead to elicitor recognition and the ensuing triggering of the hypersensitive resistance reaction.

In the present paper, we report on differences in the molecular properties of pectins extracted from cell walls of two pairs of near-isogenic wheat lines, resistant and susceptible to the wheat stem rust fungus Puccinia graminis f. sp. tritici. A preliminary report of some of these findings has been published previously (Mierau et al. 1996).

\section{RESULTS}

Cell walls isolated from leaves of two near-isogenic lines of each of the wheat cultivars Prelude and Marquis were treated with anhydrous hydrogen fluoride at $-23^{\circ} \mathrm{C}$, followed by imidazole extraction. The resulting cell wall fractions ( 2 to $4 \%$ of the total cell wall weight) were enriched in homogalacturonan (HG), as indicated by the abundance of galacturonic acid (GalA) residues and the near absence of rhamnose residues typical for the backbone of rhamnogalacturonan I or the side chains of rhamnogalacturonan II (Table 1). When the monosaccharide compositions of the two wheat cultivars were compared, only minor differences were seen, e.g., the GalA content was slightly higher in the HG fractions obtained from Marquis leaves than in those from Prelude leaves. Comparing the susceptible wheat lines Prelude and Marquis with the resistant near-isogenic lines Prelude-Sr5 and Marquis-Sr5, respectively, no resistance-related differences were obvious in the amount or composition of the HG fractions.

In order to further compare the HG fractions from resistant and susceptible near-isogenic wheat lines, an immunochemical approach was chosen, making use of the well characterized monoclonal anti-HG antibodies JIM5 and JIM7 (Fig. 1), PAM1 and LM7 (data not shown). JIM5 recognizes low ester and unesterified epitopes of $\mathrm{HG}$, binding to some extent to fully deesterified $\mathrm{HG}$ and, increasingly, to $\mathrm{HG}$ with increasing degrees of methyl esterification (DOM) up to 40\%; higher DOM strongly decrease binding of JIM5 (Willats et al. 2000). In contrast, JIM7 recognizes a more highly methyl esterified epitope of $\mathrm{HG}$, binding to $\mathrm{HG}$ with DOM ranging from 15 to $80 \%$, with an absolute requirement of at least some methyl groups for binding (Willats et al. 2000). As illustrated in Figure 1, both JIM5 and JIM7 bind more strongly to HG isolated from leaves of the susceptible wheat cultivar Prelude than to $\mathrm{HG}$ from the resistant isoline Prelude-Sr5, clearly indicating a difference in HG between samples from resistant and susceptible wheat lines. PAM1 has been described to be specific to unesterified blocks of HG consisting of more than 30 contiguous nonmethyl-esterified GalA residues (Willats et al. 2000). LM7 appears to bind preferentially to random and nonblockwise epitopes of HG (Willats et al. 2001). PAM1 weakly bound to $\mathrm{HG}$ from both isolines with only a slight preference for $\mathrm{HG}$ from the susceptible line, while LM7 bound very weakly to HG from both lines (data not shown).

The different affinities of the antibodies to HG isolated from the susceptible and resistant isolines were confirmed by competitive inhibition enzyme-linked immunosorbent assay (ELISA). Using this method, the capacity of wheat HG to inhibit antibody binding to a known immobilized antigen in solution was determined (Fig. 2). HG from the susceptible line proved to be a more effective competitor for both JIM5 and JIM7 binding than $\mathrm{HG}$ from the resistant line. $\mathrm{The} \mathrm{IC}_{50}$ (competitor concentration required to inhibit $50 \%$ of the antibody to bind to the immobilized standard pectin) of HG from resistant plants required for inhibition of JIM5 binding was fivefold higher than the $\mathrm{IC}_{50}$ of $\mathrm{HG}$ from susceptible plants (125 and 25 $\mu \mathrm{g} / \mathrm{ml}$, respectively). The $\mathrm{IC}_{50}$ of $\mathrm{HG}$ from resistant plants required for inhibition of JIM7 binding was at least twofold higher than the $\mathrm{IC}_{50}$ of $\mathrm{HG}$ from susceptible plants ( $>500$ and $225 \mu \mathrm{g} / \mathrm{ml}$, respectively). Similarly, the $\mathrm{IC}_{50}$ of $\mathrm{HG}$ from resistant plants required for inhibition of PAM1 binding was two-

Table 1. Monosaccharide composition of the homogalacturonan-enriched, imidazole soluble fraction from isolated cell walls ${ }^{\mathrm{a}}$

\begin{tabular}{lcccccccc}
\hline & \multicolumn{7}{c}{ Relative monosaccharide composition (weight \%) } \\
\cline { 2 - 8 } Wheat line & GalA & Rha & Gal & Ara & GlcA & Xyl & Glc & Man \\
\hline Prelude & 69 & 1 & 1 & 1 & 3 & 4 & 20 & 1 \\
Prelude-Sr5 & 69 & 1 & 1 & 1 & 8 & 3 & 19 & 1 \\
Marquis & 81 & 1 & 1 & 3 & 0 & 5 & 1 & 9 \\
Marquis-Sr5 & 78 & 1 & 1 & 3 & 0 & 6 & 1 \\
\hline
\end{tabular}

${ }^{a}$ Extracted from isolated cell walls of susceptible and resistant (Sr5) near-isogenic lines of the wheat cultivars Prelude and Marquis after treatment with anhydrous hydrogen fluoride (HF) at $-23^{\circ} \mathrm{C}$ followed by HF/ether and water extractions.
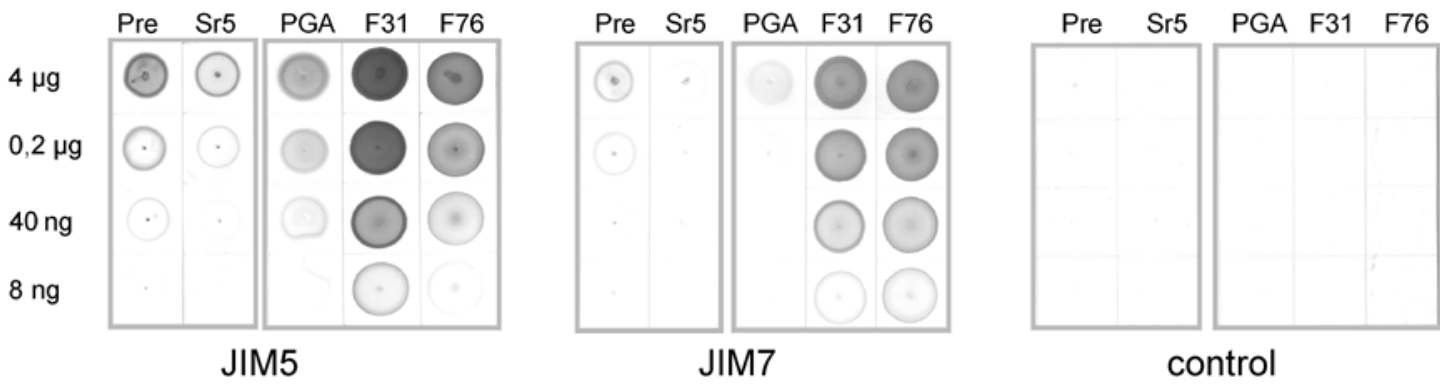

Fig. 1. Binding of the monoclonal antibodies JIM5 and JIM7 to homogalacturonan (HG) extracted from leaves of the stem rust-susceptible wheat cultivar Prelude and the resistant, near-isogenic line Prelude-Sr5, using imidazole. The HG-rich fractions, polygalacturonic acid (PGA), and two samples of standard pectins having randomly distributed methyl esters and degrees of methyl esterification of $31 \%$ and $76 \%$ were spotted as dilution series onto nitrocellulose membranes. Binding of the antibodies was visualized using peroxidase-conjugated secondary antibodies. 
fold higher than the $\mathrm{IC}_{50}$ of $\mathrm{HG}$ from susceptible plants (4 and $2 \mu \mathrm{g} / \mathrm{ml}$, respectively). No difference was seen in the $\mathrm{IC}_{50}$ of $\mathrm{HG}$ from both lines required for inhibition of LM7 (110 $\mu \mathrm{g} / \mathrm{ml})$. Thus, HG from susceptible wheat leaves binds JIM5, JIM7, and PAM1 more strongly than HG from resistant leaves, indicating differences in the methyl esterification between HGs from both isolines.

In order to corroborate and further characterize this difference, HGs from resistant and susceptible near-isogenic lines of the wheat cultivars Prelude and Marquis were analyzed chemically for their degree of methyl esterification (DOM) (Table 2). HGs from both lines of cv. Prelude exhibited a low DOM of $19 \% \pm 2 \%$ (Prelude) and 15\% $\pm 3 \%$ (Prelude-Sr5). In contrast, the DOM of HGs from Marquis and Marquis-Sr5 differed significantly, being higher for the susceptible line $(34 \% \pm 5 \%)$ and lower for the resistant line $(14 \% \pm 3 \%)$.

The distribution of the methyl esters along the linear GalA chain of HGs from susceptible and resistant wheat lines was investigated by selectively and quantitatively reducing methyl
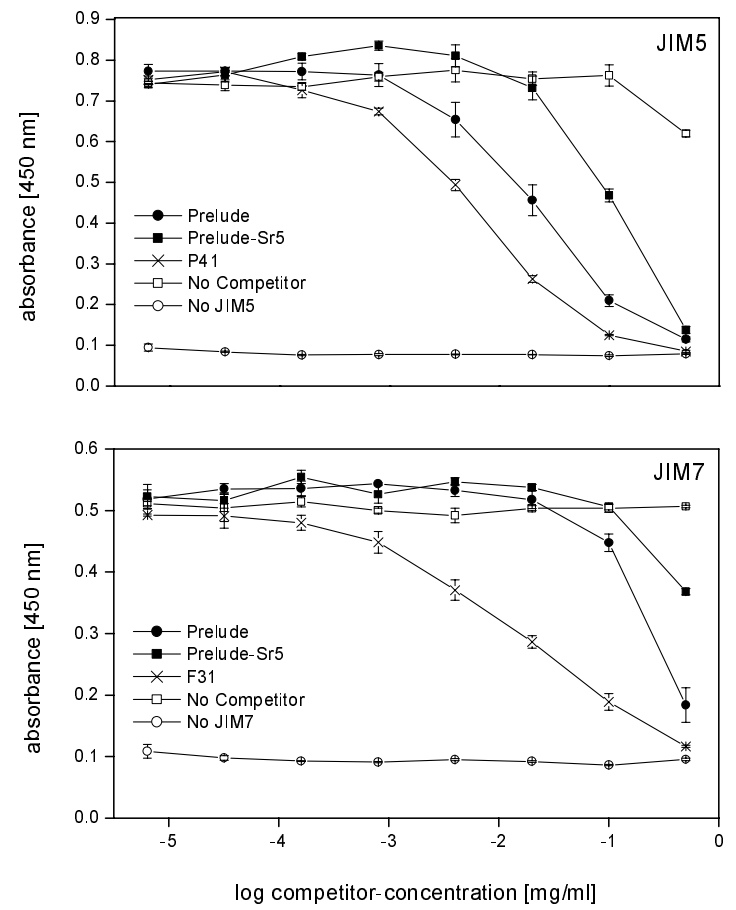

Fig. 2. Competitive inhibition enzyme-linked immunosorbent assay of JIM5 and JIM7 binding to homogalacturonan (HG) extracted from leaves of the stem rust-susceptible wheat cultivar Prelude and the resistant, near-isogenic line Prelude-Sr5, using imidazole. Standard pectins with degrees of methyl esterification of $31 \%$ or $41 \%$ and with a blockwise or random distribution of methyl esters, respectively, were immobilized in microtiter wells, and dilution series of wheat HG were added, followed by the addition of monoclonal antibodies JIM5 or JIM7. Binding of the antibodies was quantitated using peroxidase-conjugated secondary antibodies.

Table 2. Degree of esterification (DOM) of the homogalacturonanenriched, imidazole soluble fraction from isolated cell walls ${ }^{\mathrm{a}}$

\begin{tabular}{lc}
\hline Wheat line & DOM $(\boldsymbol{\%})$ \\
\hline Prelude & $19 \pm 2$ \\
Prelude-Sr5 & $15 \pm 3$ \\
Marquis & $34 \pm 5$ \\
Marquis-Sr5 & $14 \pm 3$ \\
\hline
\end{tabular}

${ }^{\mathrm{a}}$ Extracted from isolated cell walls of susceptible and resistant ( $\left.\mathrm{Sr} 5\right)$ near-isogenic lines of the wheat cultivars Prelude and Marquis after treatment with anhydrous hydrogen fluoride (HF) at $-23^{\circ} \mathrm{C}$ followed by HF/ether and water extractions. esterified GalA residues to galactose, followed by selective and quantitative solvolysis in anhydrous hydrogen fluoride (HF) of galactosyl glycosidic bonds. Contiguous stretches of nonmethyl-esterified GalA residues within the wheat $\mathrm{HG}$ were converted into GalA oligomers, which were then separated by size using high performance anion exchange chromatography (HPAEC) (Figs. 3 and 4) and individually quantified. Assuming that the methyl esters are randomly distributed, it is possible to predict how frequently each oligomer of contiguous nonesterified GalA residues would occur for any particular degree of esterification (Mort et al. 1993).

For both pairs of near-isogenic lines, a difference was seen in the spectrum of oligomers obtained from the resistant and the susceptible lines, indicative of differing patterns of methyl esterification in the parent HGs.

These differences can be seen more clearly when the logarithm of the relative peak areas of the oligogalacturonides are plotted against their degree of polymerization (DP) (Mort et al. 1993). Figures 5 and 6 give the resulting graphs for the HGs from both pairs of near-isogenic wheat lines, along with the straight lines predicted for the DOM of the respective HGs when a random distribution of methyl esters is assumed.

The experimentally determined frequencies for the different oligomer sizes from the resistant Prelude-Sr5 line closely match the theoretically expected values for randomly distributed HG methyl groups. In contrast, there is a strong difference between expectation and experimental result for the susceptible
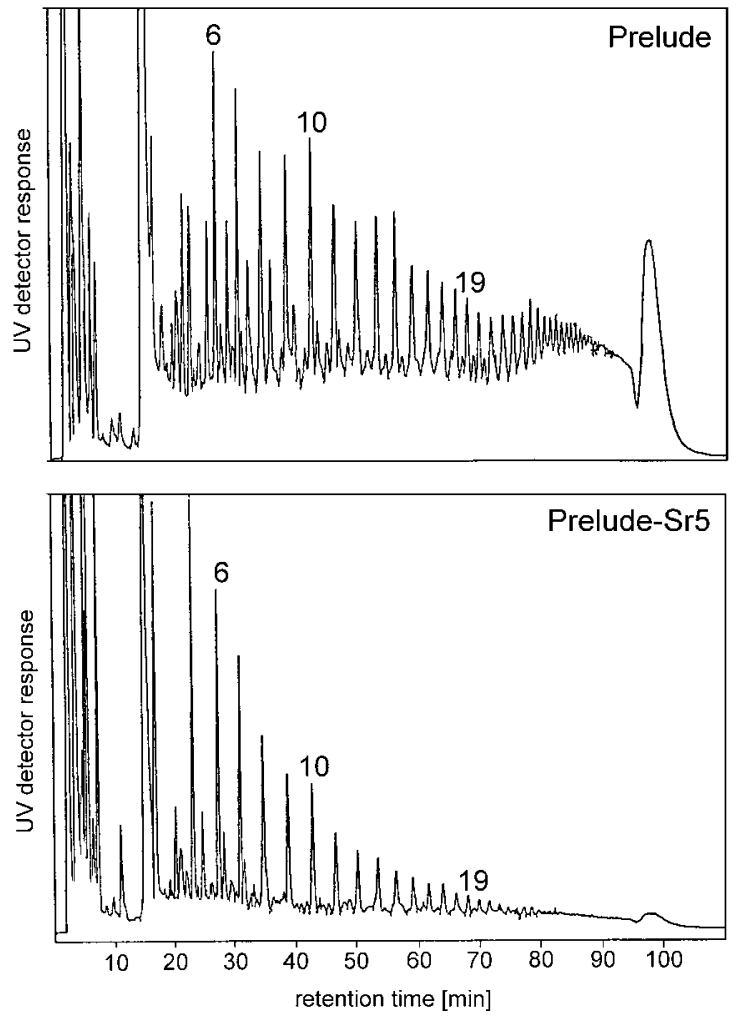

Fig. 3. High performance anion exchange chromatography separation of 2-aminopyridine-labeled oligogalacturonides carrying a galactose residue at their reducing end, generated from isolated homogalacturonan of the stem rust-susceptible wheat cultivar Prelude and the resistant nearisogenic line Prelude-Sr5 by the quantitative and selective reduction of methyl esterified galacturonic acid residues to galactose and the subsequent quantitative and selective solvolysis of galactosyl linkages using anhydrous hydrogen fluoride. Numbers in the chromatogram identify the position of standard oligomers. There is a second series of smaller peaks between the $\mathrm{GalA}_{\mathrm{n}}$-Gal peaks the nature and possible significance of which are unknown. 
cultivar Prelude. Thus, the observed frequencies of the different GalA oligomers is consistent with-though no proof for-a random distribution of the methyl esters in the $\mathrm{HG}$ of the resistant line Prelude-Sr5. In contrast, we must assume a nonrandom and more blockwise distribution of the methyl esters in the HG of the susceptible cultivar Prelude.

Unlike the Prelude lines with their very similar DOM, the Marquis lines differ in the DOM of their HGs. Nevertheless, the same and very significant difference between expectation and experimental result is again found for the susceptible Marquis cultivar, while for the resistant line Marquis-Sr5, expectation and experimental result again match rather well (Fig. 6). Consequently, the resistant line again might be characterized by a random distribution of methyl esters in the $\mathrm{HG}$, and the susceptible line again shows a nonrandom and presumably more blockwise distribution of methyl groups.

\section{DISCUSSION}

The immunological investigation of the HGs isolated from near-isogenic, susceptible and resistant wheat lines clearly indicated a difference in their methyl esterification. This finding was supported by the chemical analysis of the HGs. The immunological and chemical results can best be interpreted by assuming a nonrandom and more blockwise distribution of the methyl esters in the $\mathrm{HG}$ from susceptible plants and a more random distribution in the $\mathrm{HG}$ from resistant plants.

The chemical analysis of the HG from susceptible plants clearly indicates a nonrandom distribution of the methyl esters. Long stretches of contiguous nonmethyl-esterified GalA residues are much more frequently found than would be expected for a
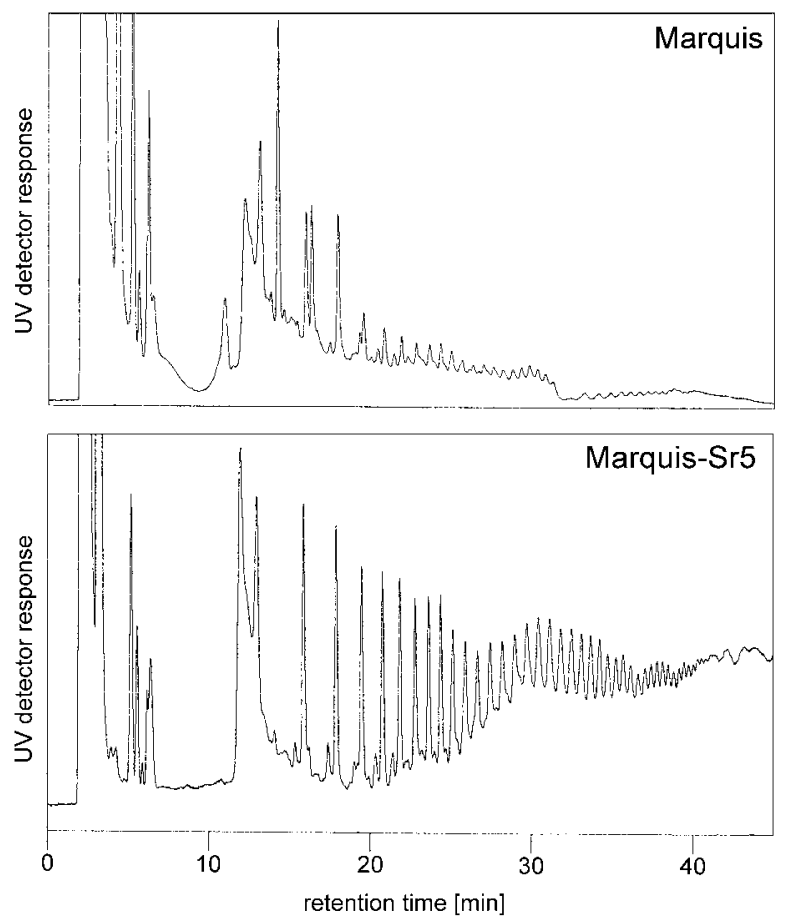

Fig. 4. High performance anion exchange chromatography separation of 2aminopyridine-labeled oligogalacturonides carrying a galactose residue at their reducing end, generated from isolated homogalacturonan of the stem rust-susceptible wheat cultivar Marquis and the resistant near-isogenic line Marquis-Sr5 by the quantitative and selective reduction of methyl esterified galacturonic acid residues to galactose and the subsequent quantitative and selective solvolysis of galactosyl linkages using anhydrous hydrogen fluoride. Numbers in the chromatogram identify the position of standard oligomers. random distribution of the amount of methyl esters present. Consequently, these very low DOM domains must be balanced by high DOM domains elsewhere in the HG of the susceptible plants. In contrast, the observed frequencies of contiguous nonmethyl-esterified GalA stretches in the HG from resistant plants is consistent with, but does not prove, a random distribution of methyl esters, as the distribution of these stretches within the $\mathrm{HG}$ molecule might be nonrandom. As an example, domains of alternating GalA and GalAMe residues might be present, but these would be degraded during the analysis to GalA-Gal dimers.

A more blockwise distribution of methyl esters would lead to both lower DOM and higher DOM domains in the HG molecules. Though the exact epitope specificities of the monoclonal antibodies are unknown, the presence of these domains may explain the preferential binding of JIM5 (medium DOM), JIM7 (medium and high DOM), and PAM1 (very low DOM) (Willats et al. 2000) to HG from the susceptible plants over that from resistant plants. A more random distribution of methyl esters might be expected to favor the binding of LM7 (medium random DOM) (Willats et al. 2001), but its behavior towards HG with low DOM $(<30 \%)$ is unknown, so the equal binding of this antibody to HGs from susceptible (DOM 19\%) and resistant (DOM 15\%) plants cannot be interpreted.

The difference in HG esterification was observed similarly in two pairs of near-isogenic wheat lines, namely, the fully susceptible cultivars Prelude and Marquis and the highly resistant lines Prelude-Sr5 and Marquis-Sr5. Interestingly, the Marquis and Marquis-Sr5 lines but not the Prelude and Prelude-Sr5 lines differed in the degree of methyl esterification of their HG. It has been found previously that the phenotype governed by
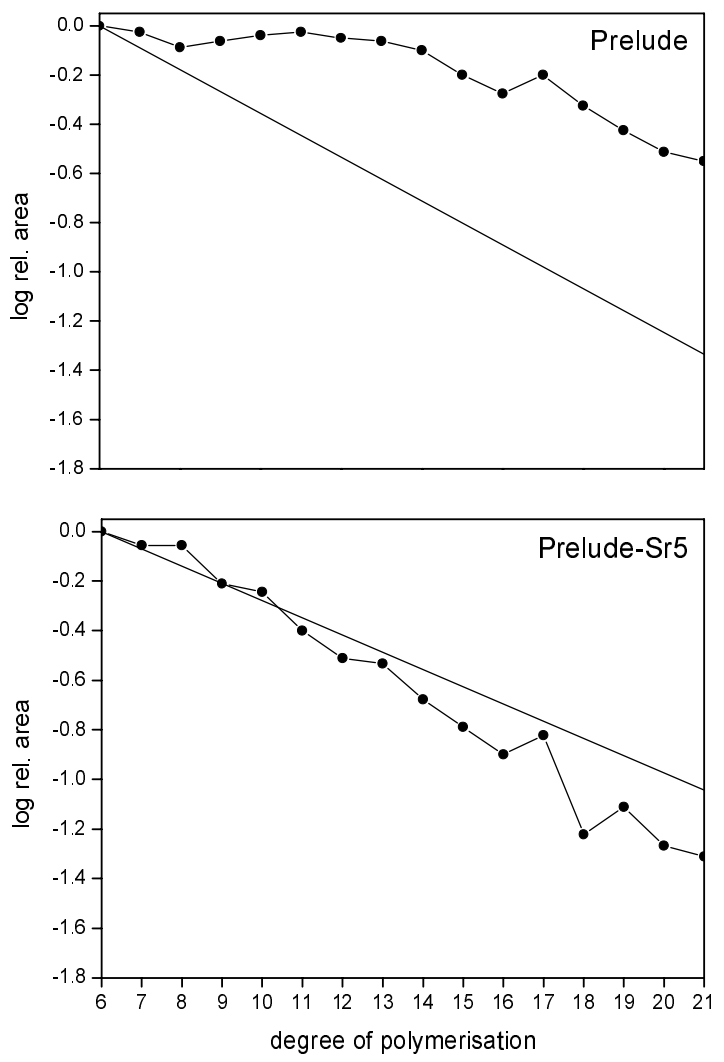

Fig. 5. Relative frequencies of oligomers with different degrees of polymerization, obtained by integration of the respective peaks in the high performance anion exchange chromatograms shown in Figure 3 and expected frequencies for a random distribution of the methyl esters, given degrees of methyl esterification of 19 (Prelude) and 15\% (PreludeSr5) (Mort et al. 1993). 
the Sr5-gene for stem rust resistance depends to some extent on the genetic background of the wheat cultivar into which the resistance gene is introgressed (Moerschbacher et al. 1989; Rohringer et al. 1979).

The HG fraction in primary cell walls is thought to be synthesized in a highly methyl-esterified form in the Golgi apparatus, followed by deposition and assembly in the cell wall (Mohnen 1999). The subsequent modulation of the degree and pattern of methyl esterification of HG is regulated by the differential activity of multiple isoforms of plant pectin methylesterases (PME) (Micheli 2001). During plant growth and development, HG methyl esterification is fine tuned to adjust the HG properties to the functional requirements within specific cell walls (Willats et al. 2001). In general, plant PMEs are thought to demethylate HG by a blockwise action pattern, producing stretches of nonesterified galacturonic acid residues (Limberg et al. 2000a and b), but plant PMEs with a multiple attack mechanism leading to a more random distribution of methyl esters have also been reported (Denès et al. 2000). Most interestingly, inhibitor proteins of plant PMEs have been identified that might modify the resulting distribution of methyl esters within the HG polymer (Balestrieri et al. 1990; Camardella et al. 2000), possibly shifting from a blockwise towards a more random pattern. It is tempting to speculate that the direct or indirect product of the Sr5-gene might possess such a PME modulating activity that would lead to loss of processivity of the enzyme.

The 'pectin hypothesis' was proposed to explain the wheatstem rust interaction governed by the Sr5-gene for rust resistance by a preferential production of endogenous pectic suppressors in infected susceptible versus resistant plants. It might now be speculated that the molecular properties of the HG in wheat cell walls might have an impact on the susceptibility or resistance of a given wheat line against the wheat stem rust fungus. Differences in the patterns of HG methyl ester groups can easily be envisaged as leading to differential degradation of $\mathrm{HG}$, thus leading to either quantitatively, qualitatively, or both, different oligogalacturonide products and, hence, different suppressor activities and differing outcomes of the host-pathogen interaction.

In other plant-pathogen systems, the composition of pectins have also been discussed to contribute to susceptibility or resistance of the host plants against their pathogens. In potato stem tissues, a higher percentage of methylated and branched pectins has been reported to correlate with resistance against the bacterium Erwinia carotovora subsp. atroseptica, and susceptible potato cultivars possess an additional PME isoform (Marty et al. 1997). A higher degree of esterification has been found in bean cultivars resistant to the fungus Colletotrichum lindemuthianum compared with that found in susceptible cultivars. When bean cell walls were digested with an endo-polygalacturonase from that fungus, the fragments recovered from resistant cultivars proved to exhibit higher elicitor activities than the fragments from a susceptible cultivar (Boudart et al. 1998). While resistant and susceptible host cultivars in these two pathosystems quantitatively differ in the degree of methyl esterification of their pectins, the difference between the nearisogenic wheat lines are more subtle in that stem rust resistant and susceptible lines differ qualitatively, most likely in the pattern of methyl esterification of their pectins. The nonrandom and assumingly more blockwise distribution of methyl esters along the HG polymer found in the susceptible wheat lines will suit depolymerizing enzymes better than the more random distribution suspected in the resistant wheat lines (Benen et al. 1999; Chen and Mort 1996; Voragen 1972; Limberg et al. 2000b; van Alebeek et al. 2002).

Electron micrographs of haustorial host cell wall penetration suggest that the growing haustorial neck of the wheat stem rust fungus performs a highly localized enzymatic digestion, since the host cell wall does not appear distorted at the site of penetration (Chong et al. 1981). The broad bean rust fungus Uromyces viciae-fabae has been shown to produce pectin-degrading enzymes during plant cell wall penetration (Deising et al. 1995). Similarly, preliminary data suggest that the wheat stem rust fungus secretes a pectin lyase during haustorial mother cell differentiation (N. Wiethölter and B. M. Moerschbacher, unpublished data). The biotrophic rye pathogen Claviceps purpurea has been described to secrete pectin-degrading enzymes during penetration into the host tissue (Tenberge et al. 1996), and knock-out mutants recently established two endo-polygalacturonases as essential pathogenicity factors of this pathogen (Oeser et al. 2002). A role of these enzymes in generating endogenous suppressors of induced disease resistance mechanisms (Moerschbacher et al. 1990, 1999) may explain the otherwise surprising importance of pectin-degrading enzymes for pathogens of pectin-poor cereals.

Using two independent approaches and using two pairs of near-isogenic wheat lines, we have clearly found a significant difference in the HG methyl esterification between stem rust resistant and susceptible wheat plants. The results can best be explained by assuming different patterns of methyl ester distribution in the HGs of the near-isogenic wheat lines. We are currently employing a third strategy to investigate the importance of these differences for enzymatic breakdown of the different HGs, using highly purified and recombinant pectin-degrading enzymes (Daas et al. 2001; Körner et al. 1999) and assaying the enzymatic products for their suppressor activities.
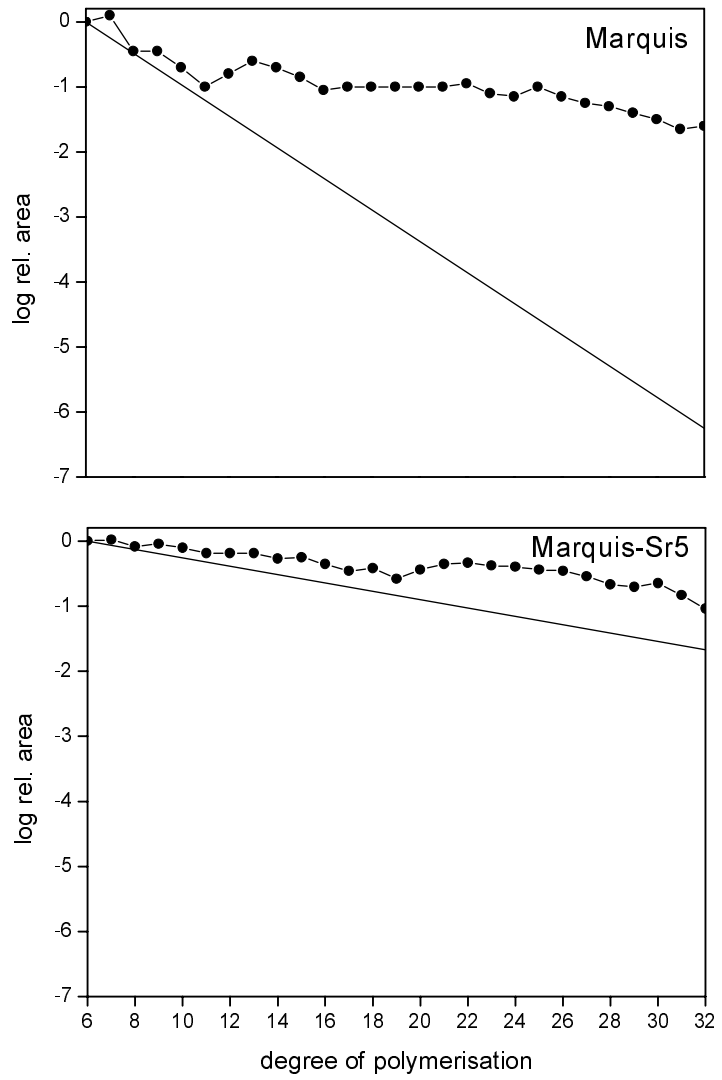

Fig. 6. Relative frequencies of oligomers with different degrees of polymerization, obtained by integration of the respective peaks in the high performance anion exchange chromatograms shown in Figure 4 and expected frequencies for a random distribution of the methyl esters, given degrees of methyl esterification of 34 (Marquis) and 14\% (Marquis-Sr5). 


\section{MATERIALS AND METHODS}

Plant materials and chemicals.

Near-isogenic wheat lines Prelude and Prelude-Sr5 (Triticum aestivum L.) and Marquis and Marquis-Sr5 (Triticum aestivum L.) (Rohringer et al. 1979) were originally obtained from the Agriculture Canada Research Station (Winnipeg, Canada) and subcultured at the Max Planck Institute for Plant Breeding (Cologne, Germany). These lines differ only in the presence or absence of the major gene for stem rust resistance Sr5. Wheat plants carrying this resistance gene are highly resistant (infection type 0 ) against the wheat stem rust fungus race 32 due to hypersensitive reaction in all penetrated epidermal and mesophyll cells. Wheat grains were soaked in water, were planted in sterilized, prefertilized garden soil, and were incubated in automatically regulated growth chambers $\left(20^{\circ} \mathrm{C}, 60 \%\right.$ relative humidity, 16-h-per-day photoperiod, 15,000 Lux). Middle sections of the first four leaves of 6- to 8-week-old wheat plants were harvested and stored at $-20^{\circ} \mathrm{C}$, prior to cell wall isolation. All chemicals used were purchased from Sigma Chemicals Co. (Taufkirchen, Germany) or Fluka Chemicals Co. (Taufkirchen, Germany), unless stated otherwise.

\section{Cell wall isolation.}

Using standard procedures (York et al. 1985), $10 \mathrm{~g}$ of frozen wheat leaves were ground in liquid nitrogen and were homogenized in $60 \mathrm{ml} \mathrm{K}$-phosphate buffer $(0.5 \mathrm{M}$, pH 7.0). After centrifugation $\left(15 \mathrm{~min}, 4^{\circ} \mathrm{C}, 1,500 \times g\right)$, the pellet was sequentially extracted in $100 \mathrm{ml}$ of methanol/chloroform (2:1, vol/vol), acetone, ethanol, and distilled water, and finally, was freeze dried, yielding about $1 \mathrm{~g}$ of dry cell walls.

\section{Imidazole extraction of wheat cell wall HG following $\mathrm{HF}$-solvolysis at $-23^{\circ} \mathrm{C}$.}

Solvolysis of wheat cell walls in HF at controlled low temperature was performed in a closed Teflon line (Mort 1983). Briefly, $500 \mathrm{mg}$ of dried wheat cell walls (precooled to $-33^{\circ} \mathrm{C}$ ) was dissolved in $20 \mathrm{ml}$ of $\mathrm{HF}$ (precooled to $-33^{\circ} \mathrm{C}$ ), and the reaction temperature was then quickly brought to $-23^{\circ} \mathrm{C}$. Thirty minutes later, the reaction was stopped by immersing the reaction vessel in liquid nitrogen. Dry ice-cooled anhydrous diethyl-ether $(200 \mathrm{ml})$ was added to the frozen HF, and the $\mathrm{HF} / \mathrm{ether}$ mixture was stirred for $30 \mathrm{~min}$ after having reached room temperature. The HF/ether was removed by filtration through a Teflon filter, the residue was washed twice with 200 $\mathrm{ml}$ of ether, and then was extracted with three changes of distilled water (6 h, $300 \mathrm{ml}$ each). The water-soluble fraction was removed by filtration, pooled, dialyzed, and freeze-dried. The water-insoluble residue was extracted three times with imidazole (0.5 M, pH 7.0) for $6 \mathrm{~h}$ and $300 \mathrm{ml}$ each. Filtration and dialysis was carried out as described above. At $-23^{\circ} \mathrm{C}$, HF cleaves the glycosidic linkages of the majority of neutral monosaccharides, but uronic acid linkages are completely stable at this temperature. Moreover, the methyl esterification of galacturonic acid is completely stable at this temperature, too (Mort et al. 1989). Thus, the above imidazole soluble fraction contains native homogalacturonan with the original in muro pattern of methyl esterification still intact (Wiethölter et al. 2003).

\section{Analysis of monosaccharide composition by capillary gas-liquid chromatography.}

HG-rich fractions isolated from wheat cell walls were digested with an endo-polygalacturonase prior to monosaccharide analysis (Quemener et al. 1989). HG samples (100 $\mu \mathrm{g})$ were dissolved in $500 \mu \mathrm{l}$ of ammonium acetate buffer $(50 \mathrm{mM}$, $\mathrm{pH}$ 5.5) containing $100 \mathrm{nmol}$ inositol and were digested with 5 to 10 units of endo-polygalacturonase (Megazyme, Bray Co., Wicklow, Ireland) overnight at room temperature, followed by drying at $50^{\circ} \mathrm{C}$ in a vacuum chamber. Following methanolysis $\left(1.5 \mathrm{M}\right.$ methanolic $\mathrm{HCl}, 50 \mu \mathrm{l}$ of methyl acetate, $80^{\circ} \mathrm{C}, 16 \mathrm{~h}$ ), capillary gas-liquid chromatography of the trimethylsilylated methyl-glycosides was performed as described previously (Chaplin 1982), using a Hewlett Packard model HP 5840A GC and an OV-1 column $(25 \mathrm{~m} \times 0.32 \mathrm{~mm}$ i.d., $0.2 \mu \mathrm{m}$ film thickness) (Macherey-Nagel, Düren, Germany).

\section{Determination of the DOM of wheat HG.}

The DOM of HG-rich fractions was determined as described by Maness and associates (1990). Briefly, methyl-esterified but not free galacturonic acid residues were selectively reduced to galactose, using sodiumborohydrate ( $40 \mathrm{ml}$ per $\mathrm{mg}$ of sample). The reduced HG was precipitated twice using ethanol, and finally, was freeze dried. A reduced HG sample $(80 \mu \mathrm{g})$ was used for monosaccharide analysis, as above. The DOM was determined by comparing the galactose and galacturonic acid contents of the samples before and after reduction.

\section{Determination of the methyl ester distribution within isolated wheat HG.}

The distribution of methyl esters along the linear HG chains was analyzed as described by Mort and associates (1993). Briefly, selectively reduced HG (discussed above) were subjected to HF-solvolysis at $-15^{\circ} \mathrm{C}$ for $30 \mathrm{~min}$, cleaving only Gal-GalA and Gal-Gal bonds but leaving intact GalA-Gal and GalA-GalA bonds (Mort et al. 1993). The GalA $\mathrm{n}_{\mathrm{n}} \mathrm{Gal}$ oligomers obtained were labeled with the fluorescent tag 2aminopyridin at their reducing ends (Maness and Mort 1989; Maness et al. 1991; Mort und Chen 1996). The 2-aminopyridinyl oligogalacturonides were separated and quantified using high pressure anion exchange chromatography on a Dionex Bio LC with a CarboPac PA 1 column $(250 \mathrm{~mm} \times 400$ $\mathrm{mm}$ i.d.). Oligogalacturonides were eluted, using a $1 \mathrm{M} \mathrm{K}$ oxalate gradient, pH 6.0 (Hotchkiss and Hicks 1990) at 0.8 $\mathrm{ml} / \mathrm{min}$, and were detected using a fluorescence detector (Shimadzu RF-535, Kyoto, Japan). The peaks obtained were annotated for their DP by comparison with the retention times of standard oligomers. Oligogalacturonide peaks were integrated for quantification, and the logarithm of the integrated areas were plotted against their DP. A detailed description of this method has been provided by Mort and associates (1993).

\section{Monoclonal anti-HG antibodies and standard pectins.}

The anti-HG monoclonal antibodies JIM5, JIM7, LM7, and PAM1 have been described in detail by Knox and associates (1990) and Willats and associates $(2000,2001)$. The standard pectins PGA (average DOM $=1.4 \%$, average DP $=220$ ), $\mathrm{F} 31$ (average DOM $=31 \%$, average DP $=380$ ), F76 (average DOM $=76 \%$, average $\mathrm{DP}=500)$, and $\mathrm{P} 41$ (average $\mathrm{DOM}=40.5 \%$, average DP $=280$ ) are described by Limberg and associates (2000a) and were provided by Danisco Biotechnology (Langebrogade, Denmark).

\section{Immuno-dot blots of wheat HG using the monoclonal antibodies JIM5, JIM7, PAM1, and LM7.}

HG-rich fractions $(1 \mathrm{mg} / \mathrm{ml})$ were dissolved in water overnight and were diluted 1:5 in water. Samples $(4 \mu \mathrm{l}$ each) were spotted by hand onto nitrocellulose (Schleicher and Schuell, Einbeck, Germany). The dot blots were air dried at room temperature overnight, and binding of anti-HG antibodies was tested as follows. Hybridoma supernatants of the monoclonal antibodies JIM5, JIM7, and LM7 were diluted 1:5 in MPBS (phosphate-buffered saline containing 5\% fat free milk powder, 
$\mathrm{pH}$ 7.2). PAM1 was used as a 1:100 dilution in MPBS of phage prepared by polyethylene glycol precipitation (Willats et al. 2000). Membranes were incubated with the primary antibodies for $1.5 \mathrm{~h}$ and, then, were washed extensively with tap water on both sides. For JIM5, JIM7, and LM7, anti-rat horse radish peroxidase conjugate (Sigma, Poole, U.K.) and, for PAM1, anti-M13 horse radish peroxidase was used as secondary antibody diluted 1:1000 in MPBS, and membranes were incubated for $1.5 \mathrm{~h}$ prior to washing them with tap water as described above. Visualization of antibody binding was carried out by adding substrate solution ( $25 \mathrm{ml}$ of deionized water, $5 \mathrm{ml}$ of 4 chloro-1-naphthol $(5 \mathrm{mg} / \mathrm{ml})$ in methanol, $30 \mu \mathrm{lof} 6 \% \mathrm{vol} / \mathrm{vol}$ $\mathrm{H}_{2} \mathrm{O}_{2}$ ). The reaction was stopped by replacing the substrate solution with tap water.

\section{Competitive inhibition (Ci)-ELISA of wheat HG using the monoclonal antibodies JIM5, JIM7, PAM1, and LM7.}

CiELISA was used to quantitatively assess binding of the monoclonal anti-HG antibodies JIM5, JIM7, PAM1, and LM7 to the HG from susceptible and resistant wheat lines in solution (Willats et al. 2000). Microtiter plates (Maxisorp, Nunc, Denmark) were coated $(100 \mu \mathrm{l} /$ well $)$ overnight at $4^{\circ} \mathrm{C}$ with the standard pectins P41 (JIM5, PAM1) or F31 (JIM7, LM7) (50 $\mu \mathrm{g} / \mathrm{ml}$ ) in Tris-buffered saline (TBS) ( $\mathrm{pH} \mathrm{7.4).} \mathrm{The} \mathrm{microtiter}$ plates were then washed extensively with tap water and blocked with $3 \%$ bovine serum albumin (BSA) in TBS (200 $\mu \mathrm{l} /$ well) for $2 \mathrm{~h}$ at room temperature. Again, the microtiter plates were washed with tap water, and competitor solution (isolated wheat $\mathrm{HG}, 1 \mathrm{mg} / \mathrm{ml}$ ) was applied as a dilution series (1:5) in 3\% BSA and TBS (100 $\mu \mathrm{l} /$ well). Hybridoma supernatants of the primary antibodies JIM5, JIM7, and LM7 were diluted 1:100, PAM1 was diluted 1:500, and $50 \mu \mathrm{l}$ were put in each well for $2 \mathrm{~h}$. After extensive washing under tap water, 100 $\mu \mathrm{l}$ of secondary antibody (discussed above) diluted 1:1,000 were applied to each well for $2 \mathrm{~h}$ at room temperature. Following a final washing step with tap water, the microtiter plates were developed with $150 \mu \mathrm{l} /$ well of a tetramethyl benzidinebased substrate. The reaction was stopped by the addition of 2 $\mathrm{M} \mathrm{H}_{2} \mathrm{SO}_{4}(30 \mu \mathrm{l} /$ well $)$, and the absorbances were read at 450 $\mathrm{nm}$. Concentrations of wheat $\mathrm{HG}$ resulting in a $50 \%$ inhibition $\left(\mathrm{IC}_{50}\right)$ of antibody binding were determined by plotting competitor concentration against absorbance at $450 \mathrm{~nm}$. Controls with no competitor were taken as $0 \%$ inhibition of antibody binding; controls with no antibody were taken as $100 \%$ inhibition of antibody binding.

\section{ACKNOWLEDGMENTS}

We would like to thank P. Knox and B. Willats for providing monoclonal antibodies and for their help with the immunological work and Danisco Biotechnology for supplying standard pectins. This work was supported financially by the Deutsche Forschungsgemeinschaft (DFG), by the Land Nordrhein-Westfalen (NRW), and by the Deutscher Akademischer Austauschdienst (DAAD).

\section{LITERATURE CITED}

Balestrieri, C., Castaldo, D., Giovane, A., Quagliuolo, L., and Servillo, L. 1990. A glycoprotein inhibitor of pectin methylesterase in kiwi fruit (Actinidia chinensis). Eur. J. Biochem. 193:183-187.

Benen, J. A. E., Kester, H. C. M., and Visser, J. 1999. Kinetic characterization of Aspergillus niger N400 endopolygalacturonases I, II and C. Eur. J. Biochem. 259:577-585.

Boller, T. 1995. Chemoperception of microbial signals in plant cells. Annu. Rev. Plant Physiol. Plant Mol. Biol. 46:189-214.

Boudart, G., Lafitte, C., Barthe, J.P., Frasez, D., and Esquerré-Tugayé, M. T. 1998. Differential elicitation of defense responses by pectic fragments in bean seedlings. Planta 206:86-94.
Camardella, L., Carratore, V., Ciardiello, M. A., Servillo, L., Balestrieri, C., and Giovane, A. 2000. Kiwi protein inhibitor of pectin methylesterase. Eur. J. Biochem. 267:4561-4565.

Chaplin, M. F. 1982. A rapid and sensitive method for the analysis of carbohydrate components in glycoproteins using gas-liquid chromatography. Anal. Biochem. 123:336-341.

Chen, E. M. W., and Mort, A. J. 1996. Nature of sites hydrolyzable by endopolygalacturonase in partially-esterified homogalacturonans. Carbohydr. Polym. 29:129-136.

Chong, J., Harder, D. E., and Rohringer, R. 1981. Ontogeny of mono- and dicaryotic rust haustoria: Cytochemical and ultrastructural studies. Phytopathology 71:975-982.

Côté, F., Ham, K.-S., Hahn, M. G., and Bergmann, C. W. 1998. Oligosaccharide elicitors in host-pathogen interactions. Generation, perception and signal transduction. Subcell. Biochem. 29:385-432.

Daas, P. J. H., Voragen, A. G. J., and Schols, H. A. 2001. Study of the methyl ester distribution in pectin with endo-polygalacturonase and high-performance size-exclusion chromatography. Biopolymers 58:195-203.

Deising, H., Frittrang, A. K., Kunz, S., and Mendgen, K. 1995. Regulation of pectin methylesterase and polygalacturonate lyase activity during differentiation of infection structures in Uromyces viciae-fabae. Microbiol. 141:561-571.

Denès, J. M., Baron, A., Renard, C. M. G. C., Péan, C., and Drilleau, J.-F 2000. Different action pattern for apple pectin methylesterase at $\mathrm{pH}$ 7.0 and 4.5. Carbohydr. Res. 327:385-393.

El Gueddari, N. E., Rauchhaus, U., Moerschbacher, B. M., and Deising, H. B. 2002. Developmentally regulated conversion of surface-exposed chitin to chitosan in cell walls of plant pathogenic fungi. New Phytol. 156:103-112.

Hotchkiss, A. T., and Hicks, K. B. 1990. Analysis of oligogalacturonic acids with 50 or fewer residues by high-performance anion-exchange chromatography and pulsed amperometric detection. Anal. Biochem. 184:200-206.

Knogge, W. 1997. Elicitors and suppressors of the resistance response. Pages 159-182 in: Resistance of Crop Plants against Fungi. H. Hartleb, R. Heitefuss, and H. H. Hoppe, eds. Gustav Fisher Verlag, Ulm, Germany.

Knox, J. P., Linstead, P. J., King, J., Cooper, C., and Roberts, K. 1990. Pectin esterification is spatially regulated both within cell walls and between developing tissues of root apices. Planta 181:512-521.

Körner, R., Limberg, G., Christensen, T. M. I. E., Mikkelsen, J. D., and Roepstorff, P. 1999. Sequencing of partially methyl esterified oligogalacturonates by tandem mass spectrometry and its use to determine pectinase specificities. Anal. Chem. 71:1421-1427.

Limberg, G., Körner, R., Buchholt, H. C., Christensen, T. M. I. E., Roepstorff, P., and Mikkelsen, J. D. 2000a. Analysis of different deesterification mechanisms for pectin by enzymatic fingerprinting using endopectin lyase and endopolygalacturonase II from A. niger. Part I Carbohydr. Res. 327:293-307.

Limberg, G., Körner, R., Christensen, T. M. I. E., Buchholt, H. C., Roepstorff, P., and Mikkelsen, J. D. 2000b. Quantification of the amount of galacturonic acid residues in block sequences in pectin homogalacturonan by enzymatic fingerprinting with exo- and endopolygalacturonase II from Aspergillus niger. Part III Carbohydr. Res. 327:321-332.

Maness, N. O., and Mort, A. J. 1989. Separation and quantitation of galacturonic acid oligomers from 3 to over 25 residues in length by anion-exchange high-performance liquid chromatography. Anal. Biochem. 178:248-254.

Maness, N. O., Ryan, J. D., and Mort, A. J. 1990. Determination of the degree of methyl esterification of pectins in small samples by selective reduction of esterified galacturonic acid to galactose. Anal. Biochem. 185:346-352.

Maness, N. O., Miranda, E. T., and Mort, A. J. 1991. Recovery of sugar derivatives from 2-aminopyridin labeling mixtures for high-performance liquid chromatography using UV or fluorescence detection. J. Chromatogr. 587:177-183.

Marty, P., Jouan, B., Bertheau, Y., Vian, B., and Goldberg, R. 1997. Charge density in stem cell walls of Solanum tuberosum genotypes and susceptibility to blackleg. Phytochem. 44:1435-1441.

Mendgen, K., Hahn, M., and Deising, H. 1996. Morphogenesis and mechanisms of penetration by plant pathogenic fungi. Ann. Rev. Phytopathol. 34:367-386.

Micheli, F. 2001. Pectin methylesterases: Cell wall enzymes with important roles in plant physiology. Trends Plant Sci. 6:414-419.

Mierau, M., Graeßner, B., Mort, A. J., and Moerschbacher, B. M. 1996. Pectins and pectinases in stem rust-infected wheat. Pages 687-692 in: Pectins and Pectinases. J. Visser and A. G. J. Voragen, eds. Elsevier Science, Amsterdam. 
Moerschbacher, B. M., and Reisener, H. J. 1997. The hypersensitive resistance response. Pages 126-158 in: Resistance of Crop Plants against Fungi. H. Hartleb, R. Heitefuss, and H. H. Hoppe, eds. Gustav Fisher Verlag, Ulm, Germany.

Moerschbacher, B. M., Flott, B. E., Noll, U., and Reisener, H.-J. 1989. On the specificity of an elicitor preparation from stem rust which induces lignification in wheat leaves. Plant Physiol. Biochem. 27:305314.

Moerschbacher, B. M., Schrenk, F., Graeßner, B., Noll, U., and Reisener H.-J. 1990. A wheat cell wall fragment suppresses elicitor-induced resistance responses and disturbs fungal development. J. Plant Physiol. 136:761-764.

Moerschbacher, B. M., Mierau, M., Graeßner, B., Noll, U., and Mort, A. J. 1999. Small oligomers of galacturonic acid are endogenous suppressors of disease resistance reactions in wheat leaves. J. Exp. Bot 50:605-612.

Mohnen, D. 1999. Biosynthesis of pectins and galactomannans. Pages 497-527 in: Comprehensive Natural Products Chemistry. Vol. 3. S. D. Barton and K. Nakanishi, eds. Elsevier, Oxford.

Mort, A. J. 1983. An apparatus for safe and convenient handling of anhydrous, liquid hydrogen fluoride at controlled temperatures and reaction times. Application to the generation of oligosaccharides from polysaccharides. Carbohydr. Res.122:315-321.

Mort, A. J., and Chen, E. M. W. 1996. Separation of 8-amino-naphtalene1,3,6-trisulphonate (ANTS)-labeled oligomers containing galacturonic acid by capillary electrophoresis: Application to determining the substrate specificity of endo-polygalacturonases. Electrophoresis 17:379383 .

Mort, A. J., Komalavilas, G. L., Rorrer, G. L., and Lamport, D. T. A. 1989. Anhydrous hydrogen fluoride and cell-wall Analysis. Pages 3769 in: Modern Methods of Plant analysis. Vol. 10. H. F. Linskens and J. F. Jackson, eds. Springer-Verlag, Berlin.

Mort, A. J., Qui, F., and Maness, N. O. 1993. Determination of the pattern of methyl esterification in pectin. Distribution of contiguous nonesterified residues. Carbohydr. Res. 247:21-35.

Oeser, B., Heidrich, P. M., Müller, U., Tudzynski, P., and Tenberge, K. B. 2002. Polygalacturonase is a pathogenicity factor in the Claviceps purpurea/rye interaction. Fungal Gen. Biol. 36:176-186.

Quemener, B., Thibault, J. F., Brunet, C., and Crepeau, M. J. 1989. Improvements in the methanolysis of pectins by enzymatic prehydrolysis. Carbohydr. Res. 190:c7-c10.
Rohringer, R., Kim, W. K., and Samborski, D. J. 1979. A histological study of interactions between avirulent races of stem rust and wheat containing resistance genes Sr5, Sr6, Sr8, or Sr22. Can. J. Bot. 57:324331.

Sutherland, M. W., Deverall, B. J., Moerschbacher, B. M., and Reisener, H.-J. 1989. Wheat cultivars and chromosomal selectivity of two types of eliciting preparations from rust pathogens. Physiol. Mol. Plant Pathol. 35:535-541.

Tenberge, K. B., Homann, V., Oeser, B., and Tudzynski, P. 1996. Structure and expression of two polygalacturonase genes of Claviceps purpurea in tandem and cytological evidence for pectinolytic activity during infection of rye. Phytopathology 86:1084-1097.

Van Alebeek, G. J. W. M., Christensen, T. M. I. E., Schols, H. A. Mikkelsen, J. D., and Voragen, A. G. J. 2002. Mode of action of pectin lyase A of Aspergillus niger on differently $\mathrm{C}_{6}$-substituted oligogalacturonides. J. Biol. Chem. 277:25929-25936.

Vander, P., Vårum, K. M., Domard, A., El Gueddari, N. E., and Moerschbacher, B. M. 1998. Comparison of the ability of partially Nacetylated chitosans and chitooligosaccharides to elicit resistance reactions in wheat leaves. Plant Physiol. 118:1353-1359.

Voragen, A. G. J. 1972. Characterization of pectin lyases on pectins and methyl oligogalacturonates. Ph. D. thesis. Wageningen University, The Netherlands.

Wiethölter, N., Graeßner, B., Mierau, M., Willats, W. G. T., Knox, J. P., Moerschbacher, B. M. 2003. Isolation and characterization of the homogalacturonan from type II cell walls of the commelinoid monocot wheat using HF-solvolysis. Carbohydr. Res. 338:423-431.

Willats, W. G. T., Limberg, G., Buchholt, H. C., van Alebeek, G. J. W. M., Benen, J., Christensen, T. M. I. E., Visser, J., Voragen, A. Mikkelsen, J. D., and Knox, J. P. 2000. Analysis of pectic epitopes recognised by hybridoma and phage display monoclonal antibodies using defined oligosaccharides, polysaccharides, and enzymatic degradation. Carbohydr. Res. 327:309-320.

Willats, W. G. T., Orfila, C., Limberg, C., Buchholt, H. C., van Alebeek, G. J. W. M, Voragen, A. G. J, Marcus, S. E., Christensen, T. M. I. E., Mikkelsen, J. D., Murray, B. S., and Knox, J. P. 2001. Modulation of the degree and pattern of methyl esterification of pectic homogalacturonan in plant cell wall. J. Biol. Chem. 276:19404-19413

York, W. S., Darvill, A. G., McNeil, M., Stevenson, T. T., and Albersheim, P. 1985. Isolation and characterization of plant cell walls and cell wall components. Meth. Enzymol. 118:3-40. 